\title{
Patients' wants versus patients' interests: a commentary
}

\author{
Eric Wilkes Sheffield University
}

No doctor is likely to deny the importance of a good doctor-patient relationship. Indeed many would say that our present difficulties make such a relationship more than ever crucial in attempting to achieve the combination of reasonable health care and a satisfied patient, but without the profligate use of resources more characteristic of American or Australian practice.

Consultation skills are more reliable and more sophisticated among the younger doctors but older colleagues have at least had years of learning from mistakes. Retirement that used to be a dreaded dressrehearsal for death is now more of a blessed relief from the pressures of the day. The profession gets younger therefore, and although medical training may still be variable and unsatisfactory, it is far less antediluvian than even a decade ago.

'Without trust' said Dr Johnson 'there can be no negotiation.' Despite being a rather disgruntled society with an in-built hostility to trained professional talent, I believe that we are achieving trust and helpful negotiation with our patients on a more massive scale than is often realised.

Indeed one of the more damaging accusations levelled at busy and compliant practitioners is that they are only too ready to go along with the expressed prescribing wants of their patients, even if the use of drugs is not clearly indicated. Again and again, one hears academics complaining wearily at the prescribing of antibiotics for a common cold or tranquillisers for stress or loss.

By and large potent modern drugs are either safe or unsafe only when weighed against the urgency of the need. Only ineffective drugs are really safe. It is therefore satisfactory that doctors tend to prescribe less quite independently of prescription charges - and that patients often express anxiety about the need to take drugs at all, although in nearly 15 per cent of cases they get prescriptions that they do not even take to a pharmacist to fill. In fact, therefore, I believe that in the everyday load of general practice we are already very much in John Wilson's world. If the doctor uses drugs as 'possibly helpful' in a case, this is often with

\section{Key words}

Doctor-patient relationship; respect for autonomy. the tacit enccuragement of the patient. I would not wish this tendency to become more apparent. Both patient and costs might be further damaged, and already some ten per cent of hospital admissions are due to problems of treatment rather than disease.

In dealing with the control of important symptoms such as pain, one cannot even begin an effective campaign without a solid partnership between patient and health professional. In rheumatic pain, if there is over-treatment, giving total freedom, an unhelpful over-use of endangered joints may follow, together with an unacceptably high level of severe drug sideeffects. In cancer pain, again the patient may need sleep and peace at night but may settle for moro alertness ind more pain by day, for often there is more to life than mere analgesia.

Similarly, or perhaps even more, in spiritual or psychological pain - and some ten per cent of cases of depressive psychosis present as pain - we need a lot of help from the patient to proffer effective help in return. The prescribing rate of antidepressives has gone up, although the drugs are reasonably unpleasant to take, but the suicide rate has not increased. Many cases of depression would recover spontaneously without treatment in a month or two. The danger-point in many cases is when they begin to improve or when relapse threatens and dosage has to be increased. The person the depressive most wants to hide this from is himself. A good relationship with the physician can be literally life-saving.

As medicine gets more demanding - for example 옥 when patients with chest disease can prolong their life only by breathing oxygen from a nasal catheter for 15 hours a day - the properly briefed patient who is involved in and in charge of his or her therapeutic regime is an essential requirement. This is especially so when the regime may have to go on for years, as with hypertension, when the drugs may cause anything from a trivial drowsiness or giddiness to impotence.

Another example of circumstances in which doctor and patient have to learn tolerantly to endure the longterm burdens of uncertainty is provided by the unsolved problem of breast cancer. Here our enthusiasm was for decades used unhelpfully to mask our fears. The reduction in the scope of surgery was partly due to the clarity with which surgeons such as 
Geoffrey Keynes saw the limitations of treatment half a century ago, but probably a larger contributing factor to that reduction was the fact that women could stoically endure surgery only if it worked. When mastectomy was felt by our patients to be both mutilating and ineffective, then the pattern of treatment began to change. This again is very much John Wilson's world.

Perhaps the most vivid of all examples of the rewards and difficulties of such patient-involvement comes in the relatively straightforward art of obstetrics. One did not need Wendy Savage to realise something of the range of principles, prejudices and implications that can intervene between the contractions of a uterus and the birth of a baby. The hair-raising documents requiring signature in certain American units to release from the danger of litigation the consulting obstetrician and thereby allow a midwife delivery in a family-room type of labour ward emphasise the conflict between the likely and the possible, between the earth-mother routine on the one hand and disaster and law-suits on the other. Like chief constables, obstetricians are on a hiding to nothing.

We have covered a considerable area of medicine circulatory and chest diseases, rheumatic, malignant and mental illness, and having a baby, in which patient non-compliance will be routine unless their wishes have already been consulted.

What then of the areas of medicine where there can be no agreed right answers? It may be worrying that a third of dying patients do not know their real situation: but when patients are asked, half want to know and half do not. And how much depends on how questions are asked?

In Byrne and Long's study of doctors talking to patients (1) one sees a comparatively limited capacity on the doctor's part to move from the fully authoritarian to the fully permissive conduct of the consultation. Byrne divided the range into seven stages and found most doctors capable of spanning only about three or four of them.

And even good communication, like patriotism, is not enough. The consultation does not take place in a centrally heated well-heeled vacuum. If he is well over sixty years of age and in end-stage renal failure the patient may want the full treatment - dialysis and eventual transplant surgery - but he is most unlikely in this country to get it. It may be less traumatic to refuse skilled surgery to an aged dement but the economic demands are inexorable and the National Health Service and its doctors must do the best they can with what they have got. In medicine we are all to some degree third world countries now. De facto rationing and patients' wishes are sometimes incompatible.

It is one of the less public but still vital functions of the doctor to protect the health-care system from what Osler called the patient's heroic thirst for medicine. This can vary from the simple refusal of an obviously useless and ill-conceived request for a skull $\mathrm{x}$-ray from a casualty in an Accident and Emergency Department to more difficult decisions. No politician worthy of the name will publicly condemn a patient to death on economic grounds: so the doctors quietly will have to do it for him. For many years now it has only been possible for patients to receive a proportion of the range of treatments theoretically available.

This sort of difficulty is far more demanding than the frequently encountered abuse or exploitation of the system of the type 'My child has had three colds in six weeks and I want to see a specialist'.

Then indeed one can fight one's corner or seek refuge in that admirable fail-safe of the second, or even the third, opinion. And because of our knowledge of the individuals concerned, we will tend to direct the referral to those colleagues whose assessments will be likely to match our own assessment of the case.

This may be unfair but we too have our problems. Our work-load, alcoholism-rate and maritalbreakdown rate are all uncomfortably high. To discuss options too long with the elderly frail, the mentally ill, the bloody-minded or the frightened and confused may not be anything like as kind and helpful as it sounds, and may strain an already over-heated system.

This is no excuse for arrogance or for cutting corners. Even with the young, we have to battle with the problems of informed consent, and this adds yet another variable. Casanova remarked that youth is a charming defect that time will correct; but he did no 8 have to deliver contraceptive advice to 14-year-old gir $\$$ that will almost certainly arouse their contempt later

Somewhere, somehow we must stop being unnecessarily paternalistic, but we must not keep passing the buck either. In John Wilson's paper there is too much potential for this buck-passing. This does not mean I resist his arguments for greater insight and respect, but that I hope these go with the job anyway.

If a treatment is available, the doctors usually want to give it and the patients to receive it. Influenza vaccines are expensive and of unpredictable value but it is easy to drum up a costly and unjustifiable demand. The distinguished surgeon will tell you that what took him longest to learn was when not to operate at all. If the baby who cries loudest gets the most milk, he may not be healthier for it in the long-term. This is especially so in a hard world when the diet is modern medical care. Even when delivered with discretion, it can still prove toxic in overdose. I am not fully convinced that up-to-date and enthusiastic physicians do not do more harm than out-dated and idle ones like me. All this surely limits the role of 'patient knows best' as a general guide.

Professor Eric Wilkes OBE DL FRCP FRCGP FRCPsych is Emeritus Professor of Community Care and General Practice, Sheffield University.

\section{References}

(1) Byrne P S, Long B E L. Doctors talking to patients. London: HMSO, 1976.

(See also following article.) 